\title{
Investigation of Residual Stresses within a Friction Welded Steel Pipeline by the Contour and X-ray Diffraction Methods
}

\author{
Igor Luis Diehl ${ }^{a^{*}}$ (D), Gustavo Cordenonsi da Fonseca ${ }^{a}$, Thomas Gabriel Rosauro Clarke ${ }^{(1)}$ \\ ${ }^{a}$ Universidade Federal do Rio Grande do Sul (UFRGS), Laboratório de Metalurgia Física (LAMEF), \\ Avenida Bento Gonçalves 9500 Prédio 43.820, 91509-900, Porto Alegre, RS, Brasil.
}

Received: November 16, 2021; Accepted: December 28, 2021

\begin{abstract}
Residual stresses (RS) in pipes welded by a fully automated friction welding process, called FRIEX, are investigated using the contour method (CM) and the X-ray diffraction method (XRD). Samples were produced using a self-developed equipment, which is based on the interaction between a consumable intermediate rotary ring and two stationary pipe sections, by varying the loading rate applied during the welding of API 5L B pipes with an API X65 ring. Mechanical and metallurgical properties were locally analyzed through metallography and microflat tensile tests. RS measured by XRD and CM showed comparable values; tensile zones were found in the pipe HAZ and compressive stresses were found in its adjacent areas. Tensile RS of approximately half the local yield strength of the components were also found, mostly on the internal surface, and their values decrease with increasing welding loads. Microflat tensile tests showed an increase in yield strength of pipe TMAZ and HAZ, with a clear influence of loading rates.
\end{abstract}

Keywords: Friction welding, FRIEX, Residual stress, X-ray diffraction, Contour method.

\section{Introduction}

Pipeline joining is one of the most critical operations in the oil and gas transportation industry. Welding for pipeline construction is generally carried out with electric arc processes, which have high associated costs due to the need for skilled operators that are responsible for the process itself and subsequent quality inspection procedures. Additionally, these processes are usually time-consuming, and numerous types of defects are commonly encountered in the resulting welds, as Unfried et al. ${ }^{1}$ claim in their study of friction taper plug welding (FTPW). These authors presented an alternative technique to arc weld cracks repairing using solid state joining process which has achieved a joint with no defects when analyzed the joint cross section by micrographs and scanning electron microscopy. The application of friction welding in pipes has the potential to significantly reduce the costs through reductions in the welding time and production of higher quality joints, with better mechanical properties.

Faes et al. ${ }^{2}$ developed a process, called FRIEX, that allows the pipeline to be welded by friction with a rotating ring, thus eliminating the need for rotation of long pipe sections. These authors observed suitable results in terms of impact toughness meeting BS EN 12732 standard $^{3}$, hardness and fairly coarse microstructure. The rotating ring is pressed between the ends of the pipes to be joined, generating friction and heat, as illustrated in Figure 1. Besides, as reported by Faes et al. ${ }^{5}$, at the end of the friction phase, the rotation of the weld ring is suddenly stopped, and the axial force is increased until a pre-set forging force is reached. Due to the heat generated by the friction between the parts there is

*e-mail:diehl@ufrgs.br a coalescence of the surfaces, and the forging force makes the excess metal flow out in the form of flash.

An equipment developed by Mattei et al. ${ }^{6}$ at LAMEF (Portuguese acronym for Physical Metallurgy Laboratory), called MASF 1500, was used to produce the samples studied in this paper through friction butt-welding. Its characteristics allow friction joining of pipes of dissimilar materials up to 16 inches in diameter and with different wall thicknesses. Although the FRIEX process does not involve fusion, the components to be welded experience severe deformation and high temperature gradients, leading to significant changes in the microstructure and mechanical properties, and to the induction of significant residual stresses along the welded joint, as reported by De Moraes et al. ${ }^{7}$, who also produced and analyzed FRIEX samples using API 5L X65 in both pipe and ring and compared its results with gas tungsten arc welding.

The assessment of residual stresses is crucial when it comes to the structural integrity of a mechanical component. Rossini et al. ${ }^{8}$ claims that among the different residual stress measurement techniques, only a small part of them allows the entire stress distribution inside the weld to be analyzed. This work presents the application of the contour method (CM) to assess residual stresses in welds by rotating ring friction. $\mathrm{CM}$, proposed by Prime and Gonzales ${ }^{9}$, has been shown to be effective in measuring and creating two-dimensional residual stress maps in engineering components when compared to stablished methods, as diffraction ones. CM offers some advantages compared to X-ray diffraction (XRD) or strain-gauge-based techniques since it is not affected by the microstructure or by the thickness of the 
component, as presented by Rossini et al. ${ }^{8}$ that measured the deformations directly where they occurred, avoiding mathematical correlations based on interactions between strain gauge surface readings and subsurface relaxation, as in hole-drilling method, for example.

The present work aims to evaluate the effect of the loading rate parameter on the residual stress distribution state of the welded joint produced with the rotating ring friction welding process, by comparing results from two residual stress measurement techniques, CM and XRD.

\section{Experimental Procedure}

\subsection{Welding}

Samples of API grade B steel pipes and rings made of API 5 L X65 steel were welded by FRIEX process (friction with a sudden forge force), a variant of the wellknown friction welding method for use in pipeline welding. The equipment used to produce samples, developed by the authors institute, LAMEF, is shown in Figure 2. Table 1 shows the chemical compositions of both pipe and ring materials while mechanical properties and components dimensions are presented in Table 2 .

The microstructure of API 5 L Grade B is composed of ferrite and perlite. The API 5 L X65 typical microstructure is composed of polygonal ferrite (PF) and martensite-austenite $(\mathrm{M}-\mathrm{A})^{10,11}$. Three welded samples were produced with a MASF 1500 friction welding machine using different combinations of loading parameters according to Tab. 3 . The choice of the weld parameters is based on the best results of the work of Buzzatti et al. ${ }^{11}$, that has found FRIEX parameters that are likely to produce approvable samples in terms of bending tests, tensile tests and absence of defects.

Buzzatti et al. ${ }^{11}$ pointed out that a pipeline route build up with API grade B steel should be cheaper than one that using API 5 L X65 pipes at a cost of mechanical strength. By the other hand, a joint with a superior material, as is the case of API 5 L X65, results in improved welded joint microstructure, which promote enhanced mechanical and metallurgical properties through the addition and optimization of alloying elements ${ }^{12}$. The impact of the choice of a superior grade in such joint should not have major impact in installations costs. For this reason, the present study intents to show the properties and residual stress output of a joint made of API 5 L Grade B pipes with rings of API 5 L X65. Details of process parameter evolution with time process are plotted in Figure 3 for sample S1. Samples S2 and S3 have similar portrayal.

Figure 4 shows the macrograph of the cross section of one of the samples after flash removal used in this study. The microstructure of the base metal of the pipe and ring was transformed during welding, having characteristics according to the region. The different regions of the weld were numbered in a sequence from 1 to 5,1 being the heat affected zone (HAZ) of the pipe where there were microstructural changes, 2 the thermo-mechanically affected zone (TMAZ) of the pipe where there was a mechanical effect combined with the entry of heat resulting in microstructural changes, 3 the interface zone, 4 the TMAZ of the ring, and 5 the $\mathrm{HAZ}$ of the ring.

\subsection{Contour method}

The CM is a destructive measurement technique that produces a two-dimensional map of the residual stresses normal to the cross section of the sample. The technique consists of measuring the normal displacements of the cross section of the sample, which are caused by residual stress relief during sectioning, in order to infer the stress state that existed in the component beforehand ${ }^{9,13,14}$. First introduced by Prime and Gonzales ${ }^{9}$, the method is theoretically based on Bueckner's principles of elastic superposition. Prime and DeWald $^{14}$ showed that for the CM measurement in pipes, a single cut in the longitudinal-radial plane would result in excessive stresses accumulated at the tip of the cut due to bending and the associated moment. Therefore, for the samples produced in this work, an initial cut was made at an angular position of the cylinder, relaxing the excessive bending moment. The cut that will be considered for the calculation of residual stresses is made $180^{\circ}$ from the first cut, as shown in Figure 5a. As the bending moment is relaxed during the first sectioning, plasticity problems are avoided.

The sample was fixed in a device that holds it on both sides of the sectioning line. After the cut, the cutting device allows the rotation of each of both parts by $90^{\circ}$, which makes the cut surface being horizontally aligned for the subsequent measurement of the topography of the sectioned surface

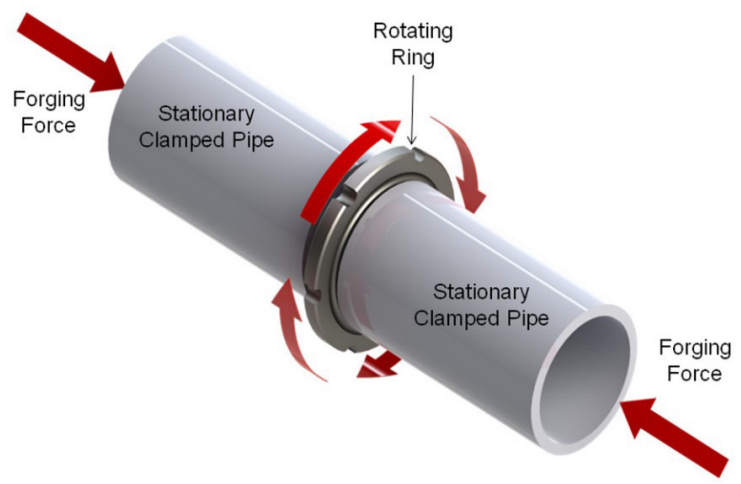

Figure 1. Pipe friction stir welding with rotating ring illustrated by Pissanti et al. ${ }^{4}$.

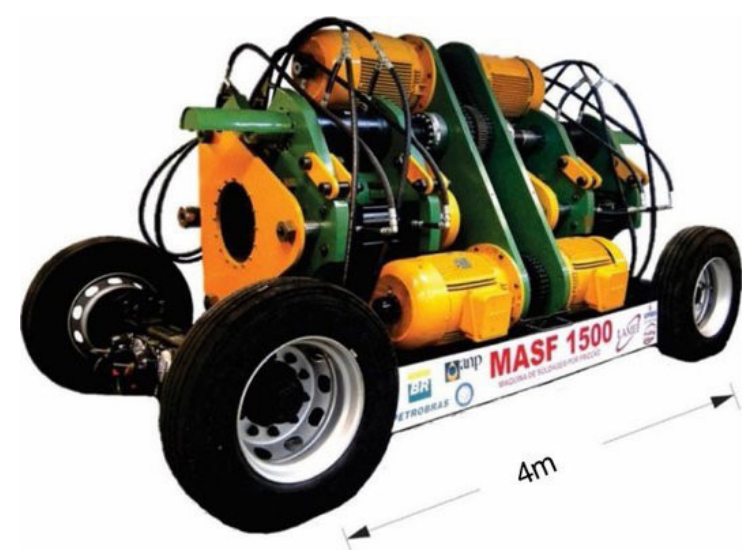

Figure 2. Welding machine, MASF 1500. 
Table 1. Chemical composition of samples materials (in weight \%).

\begin{tabular}{ccccccccccccccccccccccccc}
\hline Component & $\mathrm{C}$ & $\mathrm{Si}$ & $\mathrm{Mn}$ & $\mathrm{P}$ & $\mathrm{S}$ & $\mathrm{V}$ & $\mathrm{Nb}$ & $\mathrm{Ti}$ & $\mathrm{Ni}$ & $\mathrm{Cr}$ & $\mathrm{Cu}$ & $\mathrm{Mo}$ & $\mathrm{Al}$ & $\mathrm{N}$ \\
\hline $\begin{array}{c}\text { API 5L } \\
\text { X65 } \\
\text { (rings) }\end{array}$ & 0.174 & 0.250 & 1.128 & 0.016 & 0.0079 & 0.003 & 0.0014 & 0.0053 & $<0.01$ & 0.003 & 0.003 & 0.025 & 0.029 & 0.024 \\
\hline $\begin{array}{c}\text { API grade } \\
\text { B (pipes) }\end{array}$ & 0.098 & 0.264 & 1.41 & 0.009 & 0.003 & 0.026 & - & - & 0.015 & 0.07 & $<0.01$ & 0.05 & - & - \\
\hline
\end{tabular}

Table 2. Pipes properties and dimensions.

\begin{tabular}{lcc}
\hline & API 5 L X65 & API grade B \\
\hline Applied in & ring & pipe \\
\hline${\text { Ultimate tensile Strength }(\mathrm{MPa})^{10}}^{10}$ & 410 & 240 \\
\hline Minimum Yield Strength $(\mathrm{MPa})^{10}$ & 530 & 410 \\
\hline Outer Diameter and wall thickness $(\mathrm{mm})$ & $220.0 \times 22.0$ & $220.0 \times 12.5$ \\
\hline
\end{tabular}

Table 3. Welding parameters.

\begin{tabular}{ccccc}
\hline Sample & Loading rate $(\mathrm{kN} / \mathrm{s})$ & Preheating $(\mathrm{s})$ & Burn-off $(\mathrm{mm})$ & Rotation $(\mathrm{rpm})$ \\
\hline $\mathrm{S} 1$ & 5 & 20 & 20 & 500 \\
\hline $\mathrm{S} 2$ & 7.5 & 20 & 20 & 500 \\
\hline S3 & 10 & 20 & 20 & 500 \\
\hline
\end{tabular}

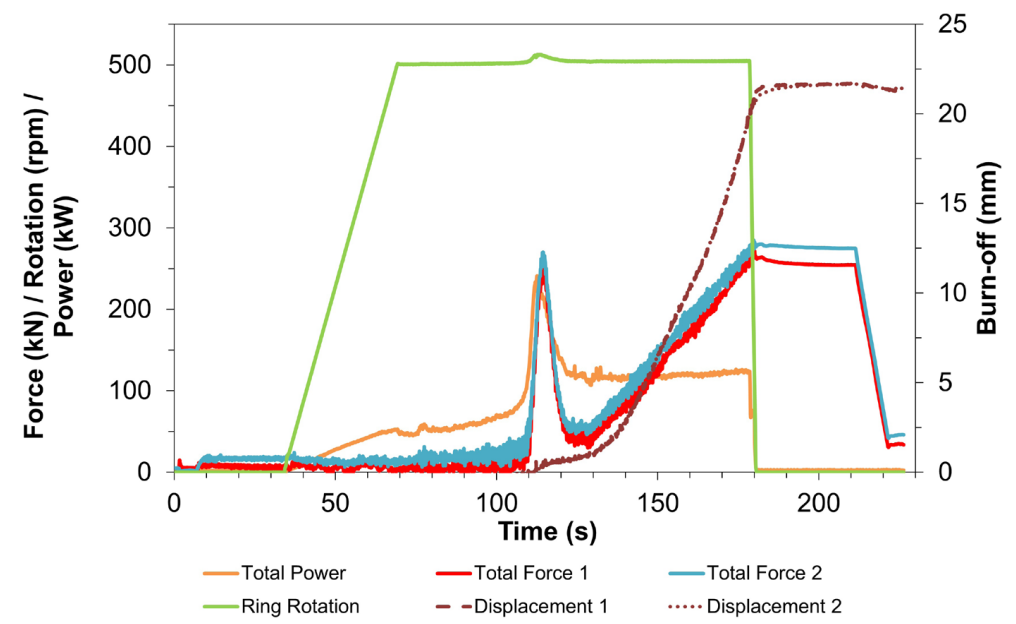

Figure 3. Welding Process Parameters of sample S1.

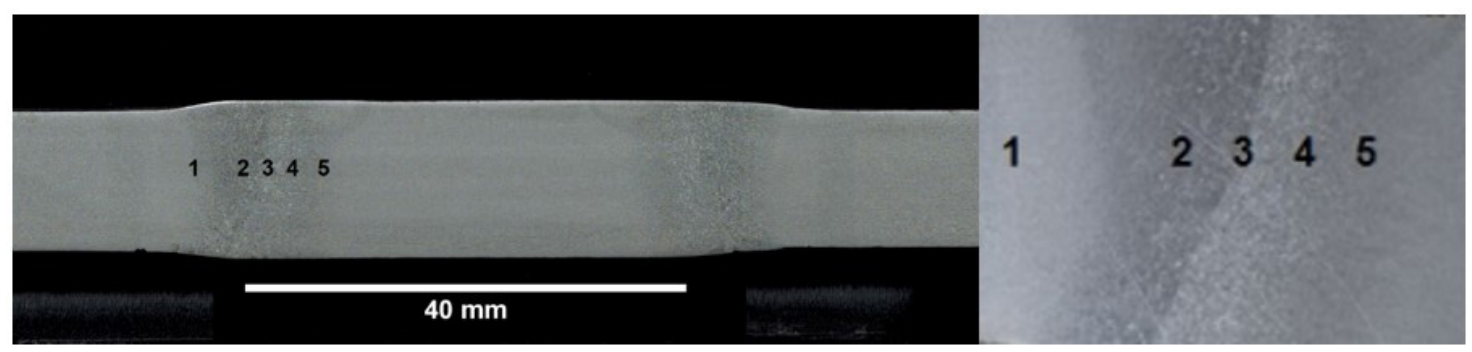

Figure 4. Microstructural sections of the welded joint: 1 - pipe HAZ; 2 - pipe TMAZ; 3 - pipe/ring interface; 4 - ring TMAZ and 5 ring HAZ. 


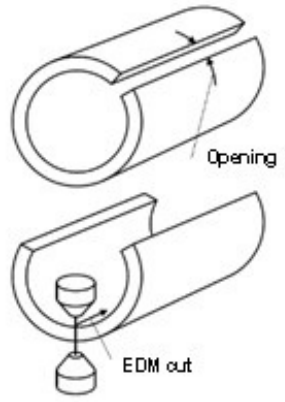

(a)

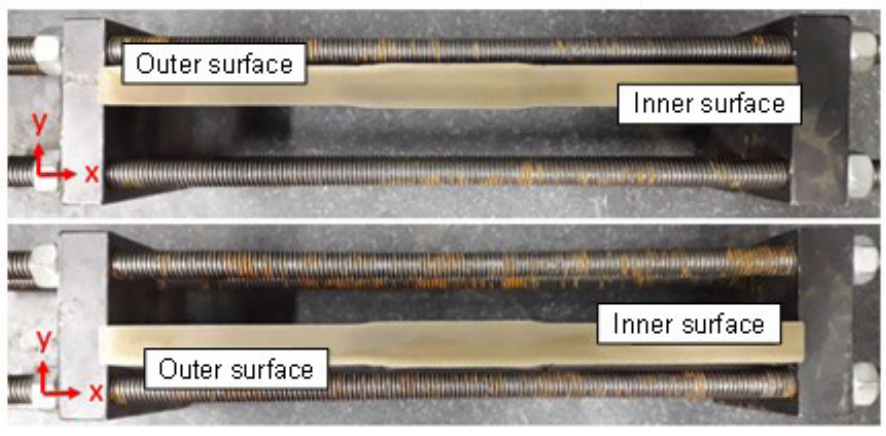

Figure 5. (a) Process of multiple sectioning for residual stress measurements in cylinders (adapted from Prime and DeWald ${ }^{14}$ ). (b) Sectioned surfaces after cut by wire EDM, horizontally aligned and ready for measurement with CMM. The relaxing displacements occurs in the normal direction of XY plane.

(Figure 5b). The sectioning was performed by wire electric discharge machining (EDM). As a result, two mirrored faces were produced (Figure 5b). The normal displacement of the cut surfaces resulting from residual stress relaxing was then measured using a coordinate measuring machine (CMM).

The measured discrete data positions from the sectioned surface went through a procedure in order to eliminate some had of the excessive variability which results from these measurements. This data smoothing step was performed with a spline interpolation which was applied through a MATLAB routine written by Johnson ${ }^{13}$.

The subsequent finite element analysis was performed in ABAQUS. The samples were modeled in a non-deformed state with the same dimensions after cutting with EDM. In this procedure, the measured profile was adjusted to the model by application of stresses in the normal direction relative to the surface in the 3D model, which contained 230,928 elements with the type of element C3D8R. The model was considered homogeneous, isotropic and elastic, with Young's modulus of $210 \mathrm{GPa}$ and Poisson's ratio equal to 0.30 .

\subsection{X-ray diffraction}

Residual stresses measurements by XRD were performed on samples $230 \mathrm{~mm}$ long and $130 \mathrm{~mm}$ wide cut from each of the welded pipe due to the diffractometer limitations. An illustration of a sample cut for XRD measurement can be seen in Figure 6. The residual stresses were analyzed in the same direction as the CM measurements, the hoop direction. It is expected some stress relaxation when the sample is cut for XRD measurements, however, the results from XRD can be compared to those from $\mathrm{CM}$, as CM experience similar relaxations. The samples were subjected to electrolytic etching of approximately $50 \mu \mathrm{m}$ depth in order to remove a surface portion affected by milling for flash removal. The $\operatorname{sen}^{2} \psi$ technique was used on a GE Seifert Charon XDR M X-ray diffractometer equipped with a $\mathrm{Cr}$ anode tube operating at $30 \mathrm{kV} / 50 \mathrm{~mA}$ and PSD Meteor1D detector. The $2 \theta$ positions of the diffraction peaks were calculated through the centroid of their area above $20 \%$ of the peak height for 11 different $\psi$-tilts equally spaced between $-60^{\circ}$ to $+60^{\circ}$. To calculate the residual stresses, the displacements of the diffraction peaks for $\alpha$-Fe 211 plane, $2 \theta=158.1^{\circ}$, were analyzed. The X-ray beam was focused through a collimator with a diameter of $2 \mathrm{~mm}$. All the different weld zones were analyzed on both the

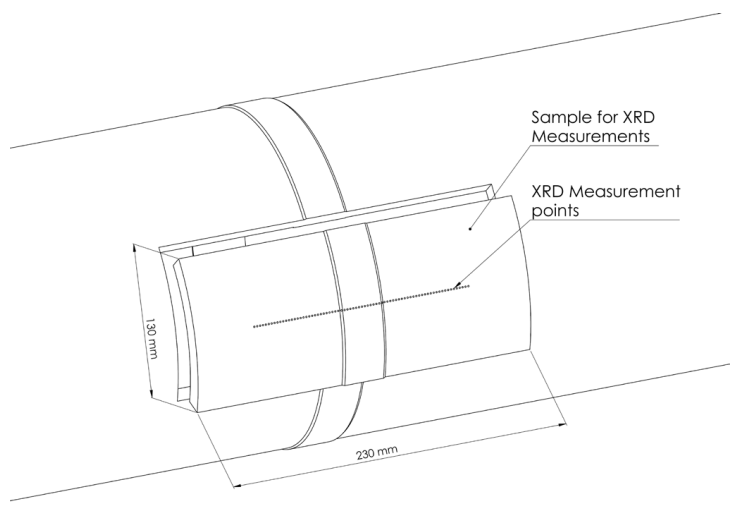

Figure 6. Illustration of sample cut from welded pipe for XRD measurements and its measurements locations.

outer surface (OS) and on the internal surface (IS) of the joint. The measurement points were spaced by $2 \mathrm{~mm}$ along the axial direction. The $\mathrm{X}$-ray elastic constants were considered $1 / 2 \mathrm{~S}_{2}$ and $-\mathrm{s}_{1}$ of $5.80 \times 10^{-6} \mathrm{MPa}^{-1}$ and $1.27 \times 10^{-6} \mathrm{MPa}^{-1}$, respectively. FWHM calculation were performed fitting the $\mathrm{k} \alpha_{1}$ peaks from residual stress data with Pearson VII fitting method, after doublets separation. The presented FWHM are the average of all peaks from the $11 \psi$-tilts of a measurement in hoop direction.

\subsection{Microflat tensile}

Tensile tests were performed with micro samples (microflat test) with a thickness of $0.5 \mathrm{~mm}$, which were extracted by wire EDM along the welded joint. Figure 7 shows the location and position at which the specimens were taken. Microflat tensile specimens were obtained from the different microstructural zones of the welded joint (pipe HAZ, pipe TMAZ, ring TMAZ, ring HAZ) and the base material. With this test, it is possible to have a detailed characterization of the local mechanical properties along the welded joint ${ }^{15}$.

\section{Results}

\subsection{Microstructure}

The initial microstructure that constitutes the base material of both pipe and ring are presented in Figure 8. It is observed 
that the microstructure of API 5L Grade B, Figure 8a, is composed of ferrite and perlite with an elongated and banded aspect related to the cold working direction. The API 5L X65 sample, Figure 8b, shows a more homogeneous and refined microstructure, composed of polygonal ferrite $(\mathrm{PF})$.

After welding, no defects were found in the analysis of the joint cross section. An increase in grain size of the equiaxial ferrite (EF) in HAZ of the pipes was observed, Figure $9 \mathrm{a}$, in comparison with the microstructure of the base material, Figure 8a. In the ring HAZ, the effect of

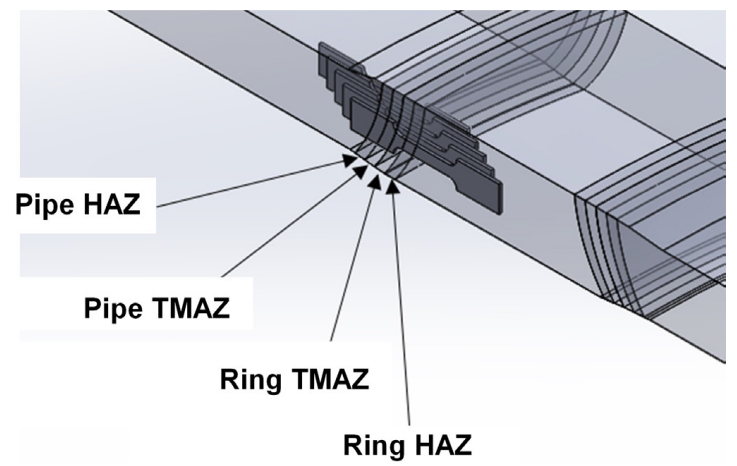

Figure 7. Schematic illustration of position of each microflat tensile sample. temperature on grain-growth is even more evident than that observed in the pipe HAZ. The longer exposure time to high temperatures in the center of the ring can explain the more prominent grain sizes in the ring HAZ; the microstructure was found to be mainly EF and aggregates of cementite/ carbides, as seen in Figure 9b.

The weld interface as well pipe and ring TMAZ are shown in Figure 10. In the regions corresponding to the TMAZ, a significant increase in the grain size of the EF was observed, showing that this weld region has gone through the recrystallization stage. In ring TMAZ (Figure 10) was observed the presence of acicular ferrite (AF) in different proportions, a microstructure similar to the pipe TMAZ, showing EF and regions composed of AF.

\subsection{Mechanical properties}

The tensile properties profiles were stablished using microflat tensile tests along the different weld zones for the three samples. Figure 11 shows the local yield stress (Rp0.2) for each of HAZ and TMAZ zones of the welded samples. The abscissa axis represents the measurement position regarding the center of the ring, where it is assumed to be the symmetry plane of weld. From Figure 11, it is generally observed that the yield stresses increase with the weld load rate. The highest yield stress limit was found to be 376,379 and $413 \mathrm{MPa}$ for samples with a loading rate of $5 \mathrm{kN} / \mathrm{s}, 7.5 \mathrm{kN} / \mathrm{s}$ and $10 \mathrm{kN} / \mathrm{s}$
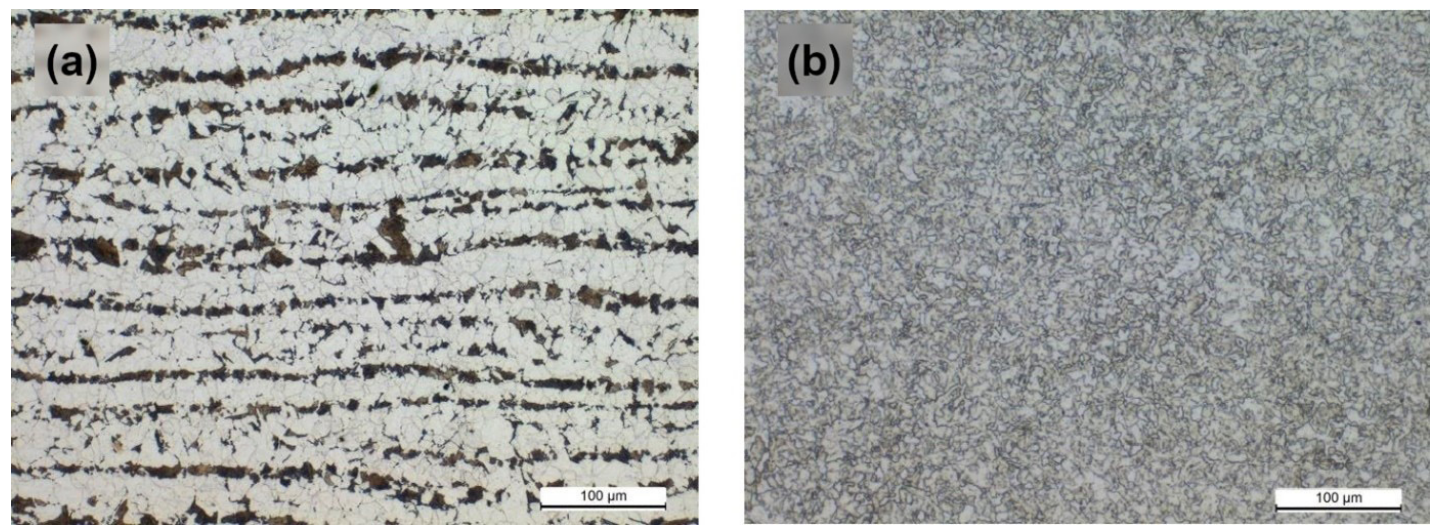

Figure 8. Base material microstructure of (a) API 5L grade B steel (pipe) and (b) API X65 (ring).
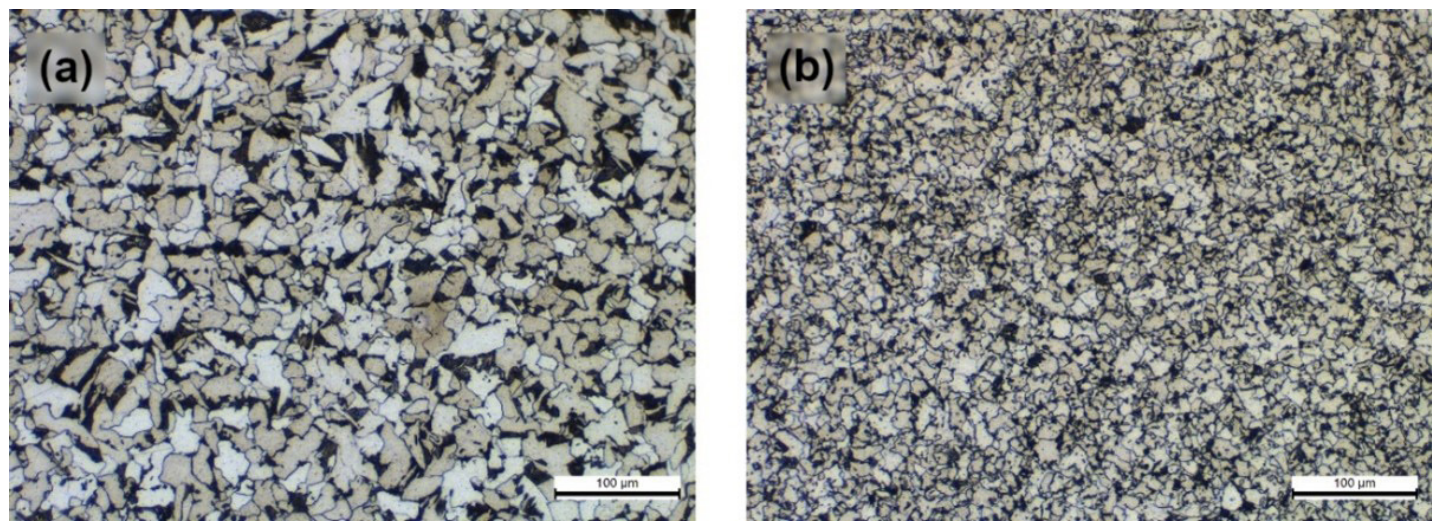

Figure 9. HAZ microstructure of (a) API 5L grade B steel (pipe) and (b) API X65 (ring). 
for the samples S1, S2 and S3, respectively, all in pipe HAZ. The lowest yield stress is found in ring HAZ for S2 and $\mathrm{S} 3$ samples, respectively $330 \mathrm{MPa}$ and $333 \mathrm{MPa}$, while there is no significant change between ring HAZ and TMAZ and pipe TMAZ for sample S1, which was found between $329 \mathrm{MPa}$ and $335 \mathrm{MPa}$. An increase in the yield strength was observed due to the change of material from API B grade to X65 as loading rate increases. This behavior is probably related to the refined

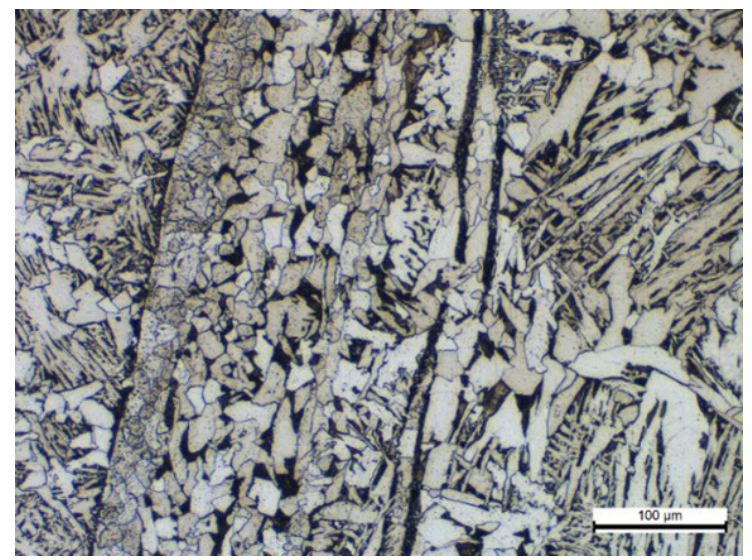

Figure 10. Microstructure at weld interface.

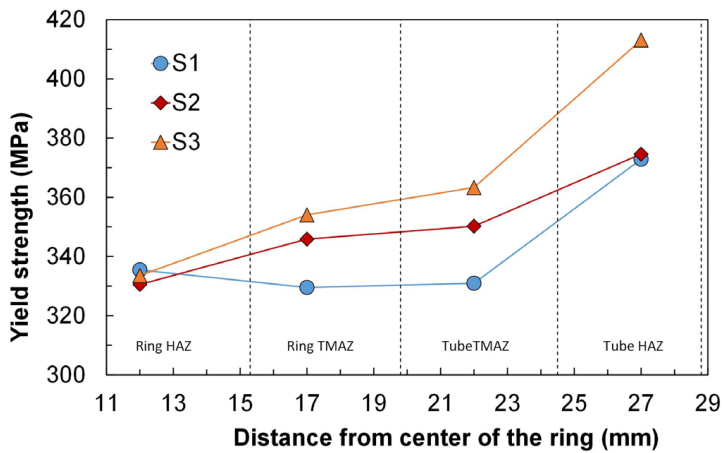

Figure 11. Yield stresses from microflat tensile test results of welded samples S1, S2 and S3.

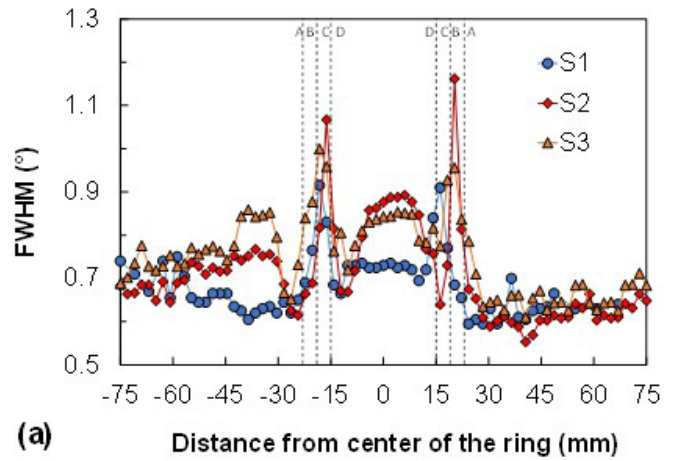

microstructure on TMAZ produced by recrystallization during the weld. Considering the yield strength of pipe and ring being $245 \mathrm{MPa}$ and $450 \mathrm{MPa}$, respectively, tensile strength tends locally to be improved in pipe portion of the joint, up to $68 \%$ with higher loading rate, and decrease in the ring portion, up to $27 \%$ with lower loading rate.

\subsection{FWHM evaluation}

From the residual stress X-ray data an important parameter can be assessed, which is the full width at half maximum of the diffraction peaks (i.e., FWHM). This parameter is dependent of grain size, dislocation density, stress state and instrument ${ }^{16}$ and can be associated with variation in hardness ${ }^{17}$. In the present work, FWHM is used to assess the change in microstructure caused by heat input and plastic deformation. Figure 12 shows the FWHM distribution due to load rate in the outer surface (OS) and inner surface (IS). A M like shape is observed in the distribution of FWHM for the three samples, in which peaks are related to the ring/pipe interface and respective TMAZ. The OS, presented in Figure $12 \mathrm{a}$, shows a maximum increase of $31 \%$ for $\mathrm{S} 1,66 \%$ for sample $\mathrm{S} 2$ and $43 \%$ for S3 in FWHM compared to the basal level, values at more than $45 \mathrm{~mm}$ from the weld centerline. Cullity and Stock $^{16}$ pointed out that a decrease in grain size increases the FWHM, and Hauk ${ }^{17}$ observed that steels with lower stress states, i.e., stress relieved, present a decrease in FWHM. Lindgren and Lepistö ${ }^{18}$ showed that FWHM values increase with plastic deformation mainly due to increases in dislocation density. These results of Figure 12 and the cited literature indicate that close to the interface there is a more pronounced increase in plastic deformation with loading rate of sample S2, as those from samples $\mathrm{S} 1$ and S3, thus increasing the FWHM. This is corroborated by the micrographs, that show refined grains in interface zones, which are caused by the high strain levels at high temperature. The smallest loading rate (i.e., sample S1) leads to small change in FWHM parameter, indicating less plastic deformation zone than welds with higher loading rate.

\subsection{Residual stresses}

\subsubsection{Contour method}

Figure 13 shows residual stresses in a two-dimensional distribution in the friction weld measured by CM of samples

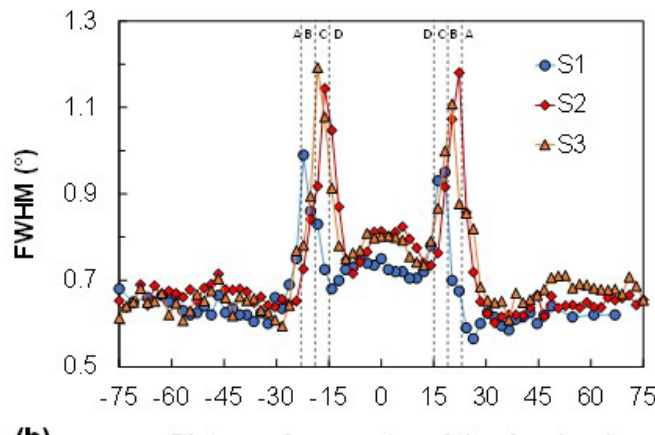

(b) Distance from center of the ring $(\mathrm{mm})$

Figure 12. Variation in the FWHM of the XRD peaks with change in loading rate. (a) FWHM in outer surface. (b) FWHM in inner surface. A-pipe HAZ, B-pipe TMAZ, C-ring TMAZ and D-ring HAZ. 

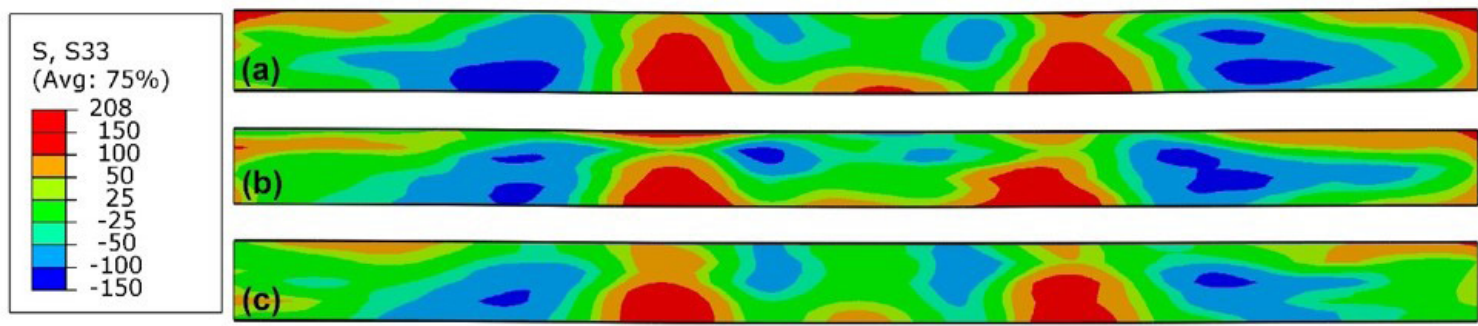

Figure 13. 2D residual stress distribution map in the circumferential direction of the welded joints (a) S1, (b) S2 and (c) S3. Values are in MPa.

$\mathrm{S} 1, \mathrm{~S} 2$ and $\mathrm{S} 3$, respectively. The measured stress is normal to the sectioned surface (stresses in the circumferential direction of the samples).

It is observed that the three samples presented tensile residual stresses in the region adjacent to the pipe/ring welding interface. With the increase in the loading rate, there is a shorter welding time, which consequently decreases the area of residual tensile stresses. From Figure 13, the samples $\mathrm{S} 1, \mathrm{~S} 2$ and $\mathrm{S} 3$ reached maximum values of tensile residual stresses, of up to $240 \mathrm{MPa}, 208 \mathrm{MPa}$ and $176 \mathrm{MPa}$, respectively. It can be noticed that on the IS of the pipe of three samples there are larger regions of tensile residual stresses that can be explained by the lower heat exchange on this surface, remaining at higher temperatures for longer.

Adjacent to the zones with tensile residual stress are the ones in which the residual stresses are compressive. This is due to the tensile region that during the welding had a high thermal input and, when cooling, this region tries to return to its original shape, reducing the residual stresses surrounding it.

Despite Pissanti et al. ${ }^{4}$ demonstrated that there is a tendency that the highest weld temperature should be found near the weld interface in FRIEX process, the highest tensile residual stress peaks are found in pipe HAZ. The pipe/ring interface also undergoes to high temperatures, but due to the compressive load applied in the forging stage, the residual stresses in this region are attenuated. The pipe/ring interface near the OS is surrounded by a mostly compressive region. This can be explained by the compressive stress applied in the forging stage that leads to a plastic flow during the last steps of the weld promoting a stress relaxation in addition to the accelerated cooling favored by the flash and ring protrusion present during welding process.

In friction welding processes, after the plastic deformation, a compressive axial stress is applied to the pipes, in the transverse direction of the weld region. De Moraes et al. ${ }^{7}$ has observed that in the FRIEX forging stage the neighborhood of the interfaces has a compressive tendency, probably due to the compressive stress applied to seal the weld, both in the circumferential and transverse directions, counterbalanced with the adjacent tractive regions.

A slight drop in both tensile and compressive residual stress from sample $\mathrm{S} 1$ to $\mathrm{S} 3$ on the OS and IS of the pipe is seen. The S1 sample obtained the highest results with $-127 \mathrm{MPa}$ of compressive stress and $183 \mathrm{MPa}$ of tensile stress, while the highest results obtained from the $\mathrm{S} 3$ sample were of $-90 \mathrm{MPa}$ of compressive stress and $167 \mathrm{MPa}$ of tensile stress, both results being measured on the pipe internal surface. It can be observed that in sample $\mathrm{S} 3$, its pipe and ring interface is in a compressive zone on both the external and internal surfaces, which may be related to its higher loading rate. Unfried et al. ${ }^{1}$ has demonstrated that in FTPW welds with lower forces have higher peak temperatures and, consequently, the higher the temperature gradients, which favors tensile residual stress state.

\subsubsection{Comparison between $x$-rays diffraction and contour method}

The contour procedure can be carried out without especific equipament or advanced residual stress measuring facilities, therefore one could consider CM to be a smooth way to measure residual stresses in pipeline. However, machining processes to prepare samples to $\mathrm{CM}$ in this work were time consuming because of sample sizes and its accuracy has to be checked prior to be implemented and used with high confidence. To check the accuracy of the contour maps the results from CM was compared with XRD measumerements. The CM profiles of Figure 14 were extracted from 2D maps presented in Figure 13, therefore, both $\mathrm{CM}$ and XRD techniques represent residual stress from same region in each case. The results depicted in Figure 14 present the comparisons on OS and IS from each of the welded samples.

When comparing the results of both methods, there is a qualitative agreement in terms of the location of the maximum and minimum stresses (Figures 14a to f). Observing the macrostructure of the welded joints (Figure 9 and Figure 10), it can be assumed that the region with the maximum compressive residual stress value was found in the regions of the pipe/ring interface and adjacent to the pipe HAZ, what was revealed by both techniques in Figure 14a to f. However, some discrepancy between CM and XRD must be noted. The transition from the nature of tensile residual stresses to compressive residual stresses occurred more abruptly in XRD analyzes, while in CM analyzes this transition took place more smoothly. Prime and Gonzales ${ }^{9}$ attributed this fact to the smoothing procedures performed in CM. As Johnson ${ }^{13}$ reported, the smaller the diameter of CMM taster, more precise and noisier are the data from measured topography. Besides that, steep gradients of residual stress may not be detected due to surface remelting depending on EDM parameters.

The measurements on OS of sample S1 (Figure 14a) show qualitative agreements when is observed the ring area (ranged between -10 and $+10 \mathrm{~mm}$ from the center of ring). The maximum XRD values in pipe HAZ also show a good agreement. The steep gradients in interface, ring TMAZ and pipe TMAZ are not followed by CM measurements, although the behavior of increasing/decreasing in residual stress is well depicted. In pipe base material, far $45 \mathrm{~mm}$ from ring center, a disagreement must be noted between CM and XRD 

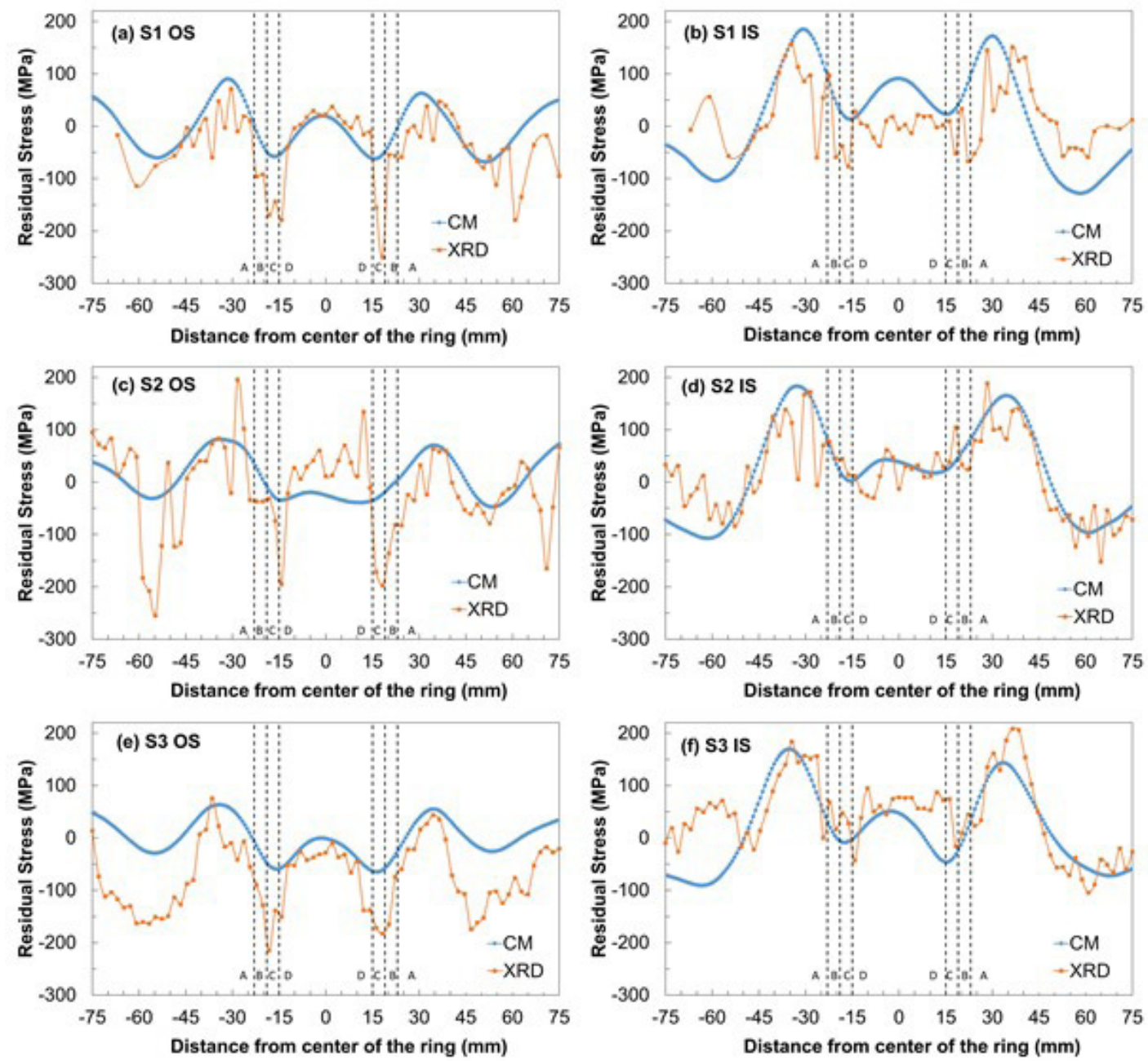

Figure 14. Comparison of residual stress measurements by CM and the (XRD) on: (a) sample S1 OS, (b) sample S1 IS, (c) sample S2 OS, (d) sample S2 IS, (e) sample S3 OS and (f) sample S3 IS. A-pipe HAZ, B-pipe TMAZ, C-ring TMAZ and D-ring HAZ.

measurements, probable due to sample distortions that are not took in count by contour measurement strategy, in which the taster followed a cartesian grid. In this way, points near the sample edge, those also assessed by XRD, can easily be missed by CMM taster.

Steep gradients in residual stress profiles are also present on OS of Samples S2 (Figure 14c), OS of sample S3 (Figure 14e), IS of sample S1 (Figure 14b) and left portion of IS of sample S2 (Figure 14d). In the absence of strong gradients, as IS of sample S3 (Figure 14f) and right portion of IS of sample S2 (Figure 14d), both techniques show similar results, despite the divergence in base material as early discussed.

The profiles by XRD also show that IS keeps more tensile residual stress than OS, although the values are lower than the residual stress found below the surface by CM. The maximum tensile residual stress found by XRD are in pipe HAZ, as show in Figure 14, being 157, 188 and $208 \mathrm{MPa}$ for sample S1, S2 and S3, respectively. The Sample S2 in its OS shows a peak of tensile residual stress of $195 \mathrm{MPa}$, also in pipe HAZ.

\section{Conclusions}

In this study, welded joints were produced using the rotating ring friction process, using three different combinations of welding parameters. Analyzes were carried out in order to investigate the residual stress distributions of the three different friction welding loading rates with microflat tensile tests in different regions of the weld.

The findings show that both $\mathrm{CM}$ and $\mathrm{XRD}$ are able to assess the residual stress state of a joint produced by friction welding with stationary pipe and rotating ring. Both techniques can describe the influence of loading rate on residual stress state. XRD and the CM analysis showed qualitative agreement of the location of the maximum and minimum stresses, the two techniques presented maximum values of tensile stress in the pipe HAZ and maximum values of compressive stress in the regions of the pipe/ring interface and adjacent to the pipe HAZ. The CM failed to capture steep gradients of residual stresses, possibly due to the procedure of the CM.

It was observed that the variation on loading rate influences the residual stress state, leading to a less tensile residual stress on OS with higher loading rate, although the 
results showed little difference in maximum tensile stress of each sample. The IS experience more pronounced tensile residual stress with high loading rate. By $\mathrm{CM}$, the welded joint with the lowest loading rate $(\mathrm{S} 1)$ presented the highest tensile and compressive residual stresses, $240 \mathrm{MPa}$ and $-150 \mathrm{MPa}$, found under the surface (Figure 13).

The distribution of mechanical properties is affected by microstructural changes experienced by material in different zones. The weld zones showed variations in the values of yield strength according to the thermal and mechanical effects developed in each zone. The highest values of yield strength and UTS obtained with microflat tensile tests occurred in the pipe TMAZ regardless the welding parameters, the higher the loading rate, the higher are the results.

The loading rate has a significant influence on FWHM. The different weld zones could be identified by FWHM variations. The variations can be observed both in high and width, indication intensity of plastic deformation and the width of TMAZ. The more pronounced increase of FWHM in weld interface is found in sample S2, indicating a more intense plastic deformation, while the less pronounced FWHM increase is found in sample S1.

\section{Acknowledgments}

The authors would like to thank the financial support from Petrobras and ANP (Brazilian Agency for Petroleum and Energy).

\section{References}

1. Unfried SJ, Paes MTP, Hermenegildo TFC, Bastian FL, Ramirez AJ. Study of microstructural evolution of friction taper plug welded joints of C-Mn steels. Sci Technol Weld Join. 2010;15(6):506-13.

2. Faes K, Vermeirsch W, De Baets P, Denys R, Van Der Donckt E. Influence of forge pressure on properties of friction welded pipelines using intermediate ring. Sci Technol Weld Join. 2008;13(5):445-51.

3. BSI: British Standards Institution. BS EN 12732: Gas Supply Systems - Welding Steel Pipework - Functional Requirements. London, UK: BSI; 2000.
4. Pissanti DR, Scheid A, Kanan LF, Dalpiaz G, Kwietniewski CEF. Pipeline girth friction welding of the UNS S32205 duplex stainless steel. Mater Des. 2019;162:198-209.

5. Faes K, Dhooge A, De Baets P, Van Der Donckt E, De Waele W. Parameter optimisation for automatic pipeline girth welding using a new friction welding method. Mater Des. 2009;30(3):581-9.

6. Mattei F, Chludzinski M, Strohaecker TR, Frainer VJ, Kroeff FC, Santos RE. Friction butt-welding machine for tubular elements. BR Patent. WO/2014/190405. 2014, Dez 4.

7. De Moraes CAP, Chludzinski M, Nunes RM, Lemos GVB, Reguly A. Residual stress evaluation in API 5L X65 girth welded pipes joined by friction welding and gas tungsten arc welding. J Mater Res Technol. 2019;8(1):988-95.

8. Rossini NS, Dassisti M, Benyounis KY, Olabi AG. Methods of measuring residual stresses in components. Mater Des. 2012;35:572-88

9. Prime MB, Gonzales RA. The Contour Method: Simple 2-D Mapping of Residual Stresses. In: 6th International Conference on Residual Stresses (ICRS6); 2000; Oxford. New York: ASME; 2000. p. 617-24.

10. Stewart M. 3 - Material requirements: piping materials. In: Stewart M. Surface Production Operations: Volume III: Facility Piping and Pipeline Systems. Boston: Gulf Professional Publishing; 2016. p. 159-92.

11. Buzzatti DT, Buzzatti JT, Lemos GVB, Amavisca CV, Oliveira DLP, Mattei F, et al. Towards friction welding to API Grade B steel pipes. J Adv Joi. Process. 2020;2:100026.

12. Sharma SK, Maheshwari S. A review on welding of high strength oil and gas pipeline steels. J Nat Gas Sci Eng. 2017;38:203-17.

13. Johnson G. Residual stress measurements using the contour method. Manchester: University of Manchester; 2008.

14. Prime MB, DeWald AT. The Contour Method. In: GS Scajer, ed. Practical residual stress measurement methods. West Sussex: John Wiley \& Sons Ltd., 2013. p. 109-38.

15. Amancio-Filho ST, Sheikhi S, dos Santos JF, Bolfarini C. Preliminary study on the microstructure and mechanical properties of dissimilar friction stir welds in aircraft aluminium alloys 2024-T351 and 6056-T4. J Mater Process Technol. 2008;206(1-3):132-42.

16. Cullity BD, Stock SR. Elements of X-ray diffraction. United Kingdom: Pearson; 2014.

17. Hauk V. Structural and residual stress analysis by nondestructive methods. New York: Elsevier Science; 1997.

18. Lindgren M, Lepistö T. Effect of prestraining on Barkhausen noise vs. Stress relation. NDT Int. 2001;34(5):337-44. 